\title{
UNA GENERACIÓN OLVIDADA DE PERIODISTAS EN LA MEMORIA DEL SIGLO XX: MANUEL GARCÍA SANTOS, VIDA Y OBRA ENTRE DOS ORILLAS
}

\author{
Lost Generation of journalism in the memory of the $20^{\text {th }}$ century: Manuel \\ García Santos, life and work between two shores
}

\author{
Laura López Romero \\ Universidad de Málaga (España) \\ José Francisco Coello Ugalde \\ Universidad Nacional Autónoma de México (México)
}

La huella periodística de Manuel García Santos fue longeva, pasional y con un verdadero afán por la supervivencia. Nacido en Jerez de la Frontera, provincia de Cádiz, y de profesión maestro, su afición por las letras lo encaminaron pronto al oficio al que dedicaría toda su vida, hasta su vejez: el periodismo. Aunque gozó de una trayectoria profesional larga y fecunda, la historia le tenía reservado, como a otros tantos periodistas, grandes obstáculos. Primero la guerra civil española, después, una dura posguerra y, por último, un exilio. Este artículo rescata de la memoria colectiva la vida de un profesional de las letras que trabajó con pasión una de sus mayores aficiones, la crítica taurina. Dos fueron los países que pudieron disfrutar de su pluma: España en sus comienzos, y México en su etapa madura y vejez. La vida de Manuel García Santos es parte del reflejo de tantos periodistas que sufrieron la represión durante la guerra civil española, pero en su caso con la fortuna de poder crear nuevos caminos que le permitieron reconstruir su oficio más querido, el periodismo, hasta su fallecimiento en México.

Palabras clave

Prensa, tauromaquia, España, México, guerra civil española
The journalistic footprint of Manuel García Santos was long-lived, passionate and with a true desire for survival. Born in Jerez de la Frontera, in the province of Cádiz (Spain), was a teacher and his love of literature soon led him to the career to which he would dedicate his entire life, until his old age: journalism. Although he enjoyed a long and profitable professional career, history had reserved for him, as for many other journalists, great obstacles. First the Spanish Civil War, then a difficult post-war period, and finally, exile. This article rescues from the collective memory the life of a professional writting, who worked with passion one of his biggest hobbies, the bullfighting chronicle. Two countries were able to enjoy his writting: his beginnings in Spain, and his maturity and old age in Mexico. The life of Manuel García Santos is part of the reflection of so many journalists who suffered repression during the Spanish civil war, but in his case, with the fortune of being able to create new paths, which allowed him to rebuild his most beloved career, journalism, until his death in Mexico.

Keywords

Press, bullfighting, Spain, Mexico, Spanish civil war 
solo a nivel local y regional, sino también nacional e internacional. Uno de los más importantes entramados periodísticos en Málaga y en el resto de Andalucía lo cimentó la familia Creixell, de origen catalán fundadora de las cabeceras de corte conservador La Unión Mercantil (1886-1936) La Unión llustrada (1909-1931) y La Unión de Málaga (19221931) (García Galindo, 1995 y 1999). olvidado no solo su vida o su obra, bién su impronta. Rescatar su memoria, sus recuerdos y sus vivencias personales y profesionales es el propósito que persigue este relato, que pretende ser una bocanada de aire fresco para entresacar del olvido a un gran profesional del periodismo en su azaroso periplo por España y su posterior exilio en México, con un escenario político de fondo muy en México, con un escenario politico de fondo muy dictadura franquista y la marcha hacia un exilio elegido y voluntario.

Esta historia permite también poner rostro al relato de tantos periodistas que sufrieron la crudeza de la represión durante la guerra civil española, la desazón del exilio y las trabas para poder ejercer libremente la libertad de prensa en un contexto político dictatorial. García Santos fue de los afortunados. Vivió una carrera profesional prolífica y longeva, dejando un extenso legado fruto de la supervivencia y la pasión por el oficio de periodista.

Manuel García Santos (en adelante MGS) nació en Arcos de la Frontera, provincia de Cádiz (España), un 8 de mayo de 1895. Cursó en Málaga estudios para ejercer de maestro y también posteriormente la carrera de Filosofía y Letras. Tras ganar las oposiciones, consiguió una plaza como maestro en la ciudad de Oviedo durante unos años.

Ya por aquel entonces, su interés por las letras y por el mundo taurino lo acercaría al mundo periodístico, en el que colaboraría en el diario Región, de Oviedo. En palabras del propio periodista, llegaría a ser director de la cabecera en aquellos años. Asimismo, iniciaría amistad con personalidades del mundo del toro, como los hermanos Bernardo y Miguel Casielles.

Casado con la asturiana Manuela Suárez García, fue padre de cinco hijos, tres varones y dos niñas. En el año 1926 solicitó una permuta para ocupar una plaza de maestro en la provincia de Málaga, lo que le permitió regresar a la ciudad donde años atrás vivió y finalizo sus estudios universitarios. En 1936 año del golpe de Estado, hay constancia documental de su posición como maestro en la Unitaria de niños de Churriana, Málaga (Pozo Fernández, 2001). Su llegada a Málaga se dejó notar pronto en la prensa de la ciudad, donde colaboraría en respetados e importantes periódicos a partir de los años

Por aquel entonces, la ciudad de Málaga vivía sus años dorados en el sector periodístico. Adaptada ya a la etapa del periodismo empresarial y noticiero, contaba con una extensa y variada producción de cabeceras, algunas de las cuales eran referencia no

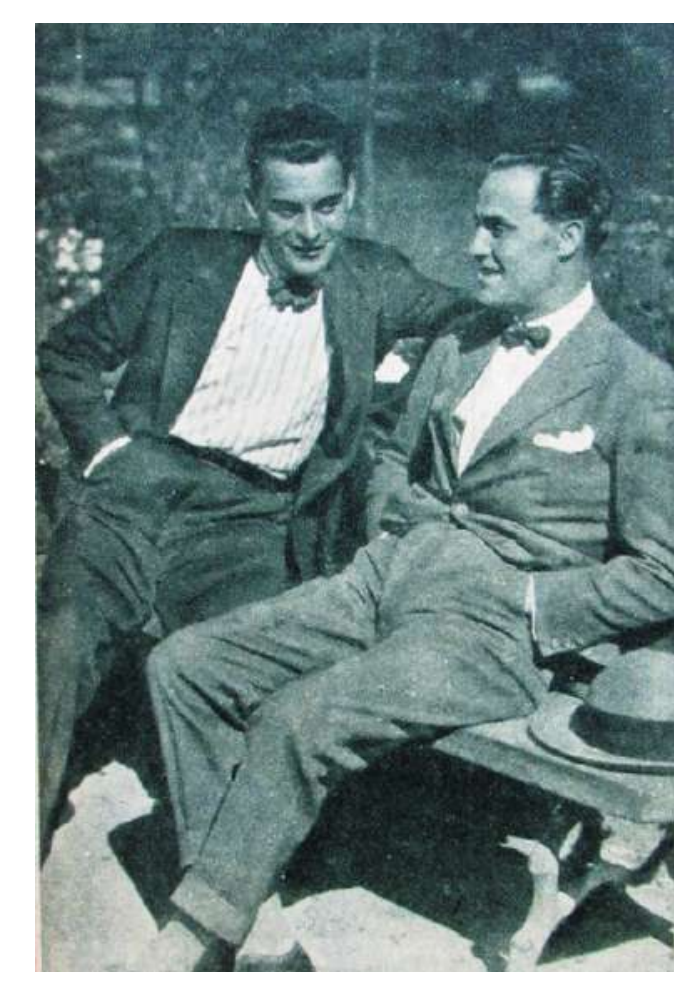
les. (Fuente: El Ruedo de México, 29 de noviem bernardo Casie-

Desde enero de 1930 a abril de 1931, MGS colaboró en La Unión llustrada, el semanario de información gráfica y literaria de mayor difusión malaguena durante las tres primeras décadas del siglo XX. En la sección «De la vida que pasa», a página completa, MGS trato sobre temas sociales y tamTambien duranta para escribir textos literarios. También durante esos años inicia su colaboración en el gran diario malagueño La Unión Mercany. y entrevistas en las secciones «Lo que nos dice" , Escucha, malagueño», «Nuestros reportajes: como tacen las cosasn, así como crónicas deportivas MGS te no, directo y respetus siempre con un tono cercaamable, cuidado y a la vez vivaracho y hasta humo-
Manuel García Santos (a la derecha) durante su estancia en Ovieimportancia de los que se publicaron en la ciudad rístico. Aunque también escribió sobre la actualidad informativa en España, apenas trataba contenido político, derivando sus comentarios más hacia una interpretación histórica, cultural y literaria del país.

Sin duda, su afición a la tauromaquia fue su más predilecta especialización en prensa desde sus inicios hasta el final de sus días. Sus amistades -entr ellas la de Álvaro Domecq-, contactos y el amplio desarrollo de la tauromaquia en la ciudad de Málaga generaron un clima de gran satisfacción personal y profesional para el periodista:

Cuando dirigía yo en Málaga La Unión Mercantily hacía en ella la crítica de toros, pude medir hasta dónde llegaban los conocimientos del público de Málaga y lo sano de aquella afición, que es, indiscutiblemente, de las mejores que hay en España. (Lunes de Excélsior, 10 de agosto de 1964, p. 10).

En esa declaración ya se puede apreciar el trato cercano que tuvo con la familia Creixell, propietaria del diario. Tanto fue así que ocupó el puesto de redactor jefe al frente y posteriormente el de director. Según palabras del propio periodista:

Dirigía yo por aquel entonces La Unión Mercantil en Málaga, por lo que ello debe haber sucedido entre 1931 y 1935. (García Santos, 1947).

Su posición en el panorama periodístico en la década de los años treinta fue importante. De he cho, llegó a presidir la Asociación de la Prensa de Málaga, según relata él mismo. Posiblemente ostentó este cargo en algún momento entre 1930 y 1936.

La vida de MGS sufrió un importante revés, a igual que la del resto de ciudadanos, cuando estalló en España el golpe de Estado del 18 de julio de 1936 contra el gobierno legítimo de la República. Por aquel entonces, ocupaba el puesto de director de La Unión Mercantil. Contaba cuarenta y un años de edad.

El diario conservador sufrió un nuevo incendio -el primero fue en 1931 con el advenimiento de la Segunda República-, provocado el mismo día del golpe de Estado (García Galindo, 1995; Vázquez 2011; López Romero, 2020). En sus memorias, el periodista Juan Cortés Salido, también redactor de La Unión Mercantil y amigo personal de MGS, relató aquellos instantes de agonía:

Al piso de Juan Barroso [vivienda anexa a las instalaciones del diario] subimos Manolo García Santos y yo que estábamos en La Unión cuando comenza作 co de la madrug primeros claros del dia, a las cinpeligros y marchar a nuestras viviendas.
La Unión Mercantif

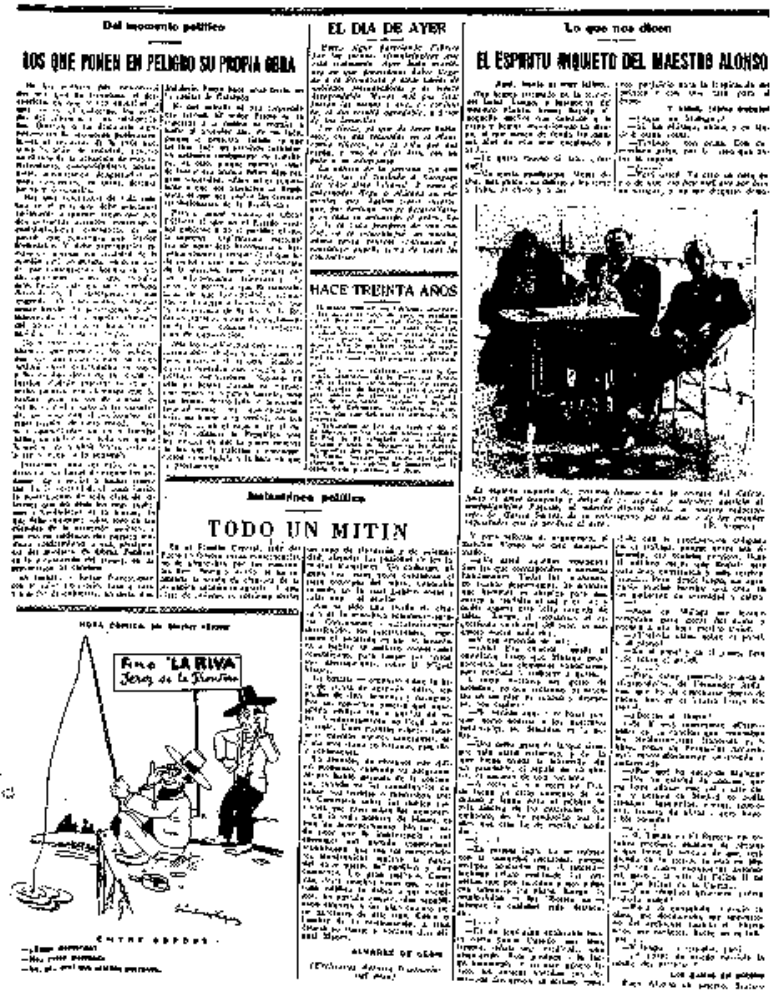

Manuel García Santos, a la derecha de la fotografía (Fuente: La Unión Mercantil, 15 de marzo de 1933, p. 1).

Una hora después, La Unión Mercantil era pasto de las llamas. (Cortés, 1952, p. 220).

A raíz de este acontecimiento histórico, MGS y dor se vieron involucrados en una maraña judicial que para algunos tendría consecuencias graves de denuncia y prisión.

En la documentación judicial que consta sobre el expediente de MGS', se ha podido comprobar que el 18 de julio se encontraba en la redacción del diario La Unión Mercantil y que tuvo que permanecer alli durante toda la noche, dadas las incidencias hasta que la sede fue asaltada y quemada. Marchó ese día a su casa y alli estuvo varios dias encerrado . riódico de derechas. En su testimonio informó de que unos amigos suyos se habian acercado hasta su casa y le habian dado un carnet falso de La Gráfica (entidad afecta a la UGT) por si eso le podía ayudar en esos días de incertidumbre, pero le ha-

'Procedimiento sumarísimo de urgencia número 13. Juzgado
militar número 15. Caja 637. Archivo Juzgado Togado Militar de Málaga. 
bían advertido que lo utilizara con mucha cautela, porque, si se descubría que era falso, tendría graves consecuencias. Ante los asesinatos de algunos directores de periódicos de derechas aquel verano caliente de 1936 -como Vicente Davó de Casas, del Diario Málaga, y Eduardo León y Serralvo, de El Cronista (García Galindo, López Romero y Novas de la Federación de las Artes Gráficas para salvar su vida.

Tras la desaparición del diario conservador, se organizó una protesta por parte de los empleados para formar una comisión que organizara los fonpara formar una comisión que organizara los fondos necesarios con el objeto de atender la manuse habían quedado en la calle. Las unimeras ayudas recibidas fueron gestionadas por el periodista en su cargo de director, pese a que posteriormente confirma ante la justicia que, por miedo a que los teléfonos estuvieran intervenidos, se había ofrecido a ayudar a la comisión para rescatar dinero y repartirlo entre los empleados.

Parte del dinero conseguido vino, primeramente, del presidente del consejo de administración, Antonio Baena; otras partidas procedían de la compañía de seguros; y también directamente del bolsillo de Ángel Creixell, hijo del fundador de diario el cual fue finalmente detenido y fusilado en 1936.

Este clima fue tremendamente complicado para muchos de los trabajadores del diario, pues su condición de periódico conservador hizo que, a ojos de las fuerzas de izquierdas, fueran considerados como sospechosos favorecedores de la causa franquista (López Romero, 2020).

Se barajó durante un tiempo la posibilidad de adquirir nueva maquinaria y restaurar el periódico, tal y como escribe de su puño y letra MGS en una carta mecanografiada el 7 de agosto de 1936 y dirigida a Antonio Baena, detenido en la prisión provincial por aquel entonces.

Dos han sido nuestras directrices. A) Reconstrucción del periódico. B) Percibo de haberes y jornales [...]. Las dos aspiraciones son legitimas; pero están en oposición, solo se cuenta con el dinero está la cifra, pudiera B) de prolongarse imposibilitar A) [...]. Conocida la situación floreciente de su crédito en los bancos locales, rogarle de nuevo, y esperamos de su espíritu comprensivo y benévolo que así lo haga, sea usted quien avale la operación de crédito que don Angel Creixell acepta, operación que lo resuelve todo y que a usted en firme de renca, pues será hecha sobre la base cargo al seguro, apenas este se cobre.

El dinero ofrecido por parte de Ángel Creixell antes de ser detenido y asesinado desencadenó un año después una denuncia que llevó a juicio a todos los empleados del diario que habían aceptado percibir esa ayuda económica. Dicho aval se consideró ilegítimo y Ángel Creixell se vio obligado a entregarlo de su propio bolsillo, según la denuncia

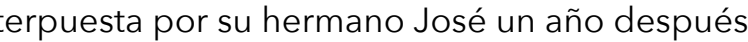

Durante los difíciles meses que transcurrieron tras el golpe de Estado, MGS recibió el encargo de colaborar en el periódico anarquista Faro. Primeramente, como maquetador y posteriormente, como me

Según el propio MGS, en su relato de confesión anul septiembre de 1936, dos individuos armados entraron en su casa, siendo uno de ellos Santana Calero, director del diario anarquista Faro, y le propusieron que ayudara en la tirada del diario. $S$ u pruda se limitaba al aspecto técnico de encajar artículos. Sin embargo días después, viendo su bue列 ción, según su testimonio.

Gracias a la documentación judicial en torno al expediente de MGS, se han rescatado algunos testimonios de lo que supuso para el periodista esta situación Según la mayoría de estos alegatos, se in terpeló al tibun la mara que el miedo obrase ce ineximente ante la causa.

Según Porfirio Smerdou, cónsul de México en Málaga, el periodista le pidió un pasaporte para huir, pero aquel, al saber lo conocido que era, no pudo acceder a su petición. En el sumario se incluye una carta del cónsul que confirma estos hechos. En él explica cómo MGS no tuvo más remedio que acceder a colaborar en Faro:

En el curso de un encuentro casual en la calle un día, hube de manifestar a García Santos mi extrañeza por ello, ya que conocía por los muchos años de trato que mantuve con él cuando estaba en $L$ a Unión Mercantil cuáles eran sus verdaderos sentimientos. Entonces García Santos me hizo comprender su situación explicándome cómo se halaba materialmente secuestrado por tan siniestro personaje [...]. Me envió una carta en la que $\mathrm{m}$ cho con muchas otras personas de orden de Mála ga, tratase de ponerlo fuera de aquí por cualquier procedimiento que viese viable, y venía redactada esta carta en términos de tal angustia que me hicieron comprender la tragedia que vivía este hombre obligado a convivir y a colaborar con un hombre de ideas tan opuestas como Santana

aración de Porfirio Smerdou, cónsul de México en Málaga 6 de marzo de 1937. Incluida en el procedimiento sumarísim Archivo Juzgado Togado Militar de Málaga.
También la prensa de derechas, en este caso la Tición sevillana del diario $A b c$ defendió la labor de MGS y su trabajo en el diario Faro:

En julio, bajo amenazas y obligados por las circunsterastantes redactores de La Unión Mercantil. El director de este diario pasó a ser asesor técnico del periódico anarquista Faro, dirigido que firmar cosas que... Yo se hentía nás remedio que firmar cosas que no se sentían ni mucho me-
nos. (Abc, edición Andalucía, 9 de marzo de 1937 . nos. (Abc)

Un texto periodístico manuscrito y firmado por MGS pendiente de publicación en Faro fue finalmente la causa directa para su procesamiento.

El instructor admite que el procesado no fuera muy selecto de la criminalidad malagueña, ya que es selecto de la criminalidad malagueña, ya que es
imposible olvidar que Faro era órgano anarquista y está en la mente de todos la intervención de las Juventudes Libertarias en los asesinatos y horrores que soportó esta población [..... Pero la copia de a este encartado el fatídico Santana Calero, pone bien claro de manifiesto que las relaciones entre aquel y los elementos disolventes y criminales anarquistas se estrecharon, al extremo de fraternidad de que aquella es exponente [...]. Confiesa el propio procesado [...] su colaboración en la redacción y el envio a Santana con ánimo de publicación del artículo «Septenario», en el que según las propias
manifestaciones del procesado, se hacía un elogio encendido de la personalidad del tal citado Santana Calero ${ }^{3}$.

Durante su proceso judicial, MGS tuvo que resdel diario conservador El Cronista, así como por las muertes de Angel y Antonio Creixell, miembros del comité de administración de La Unión Mercanti e hijos del fundador del diario. Sin duda, tuviero que ser momentos de gran dureza. Ninguna causa pudo demostrar su vinculación con sendos críme-

Según consta en el auto resumen del sumario núm. 29 del juzgado militar num. 6 , a fecha de de noviembre de 1939, MGS fue condenado a una pena de doce años y un día de reclusión. Tras diecisiete meses en la prisión provincial de Málaga MGS solicitó un indulto el 17 de agosto de 1938. La solicitud vino acompañada de una carta manuscrita del periodista, fechada el 2 de agosto de 1938.

Auto resumen del instructor en el auto procesal a Manuel García Santos, 11 de marzo de 1937. Procedimiento sumarísimo de urJuzgado Togado Militar de Málaga.
En ella, García Santos pedía una conmutación de la pena a seis meses o la condonación total. En su defensa, MGS acusó a Santana Calero de dejar el artículo escrito por el periodista visible cuando las tropas franquistas entraron en la ciudad. Según él, para perjudicarle por su «insincera amistad». Ese artículo, acerca de un bombardeo aéreo sobre la ciudad, nunca llegó a publicarse y en él se alababa ro, causa que contribuyó finalmente a su procesamiento y reclusión en prisión.

Finalmente fue aceptada la petición de indulto y puesto en libertad el 18 de junio de 1939.

En los años posteriores a su liberación, apenas se han encontrado alusiones a estos terribles y convulsos años. Una breve línea se rescata del libro que firmó sobre el torero Manolete:

Legó la guerra y, con ella, aquel bache y aquella desorientación que España tuvo. (García Santos,

Tras la concesión del indulto, MGS abandona Málaga después de un triste y grave episodio que fácilmente pudo costarle la vida. Debido a lo delicado de la situación, decidió poner tierra de por medio, abandonó la ciudad malagueña y puso rumbo a Madrid junto a toda su familia. Allí continuó con su mayor afición, convertida ya de facto en su profesión: periodista.

Hay constancia del desempeño de su labor periodistica en varios diarios. Colaboró como crítico taurino en el semanario El Ruedo (Ramón Carrión, 2010, p. 108). También para la revista Gol firmó textos entre 1942 y 1944 sobre crítica teatral, crónicas taurinas y columnas de opinión con temática social. Y además colaboró en el diario Marca. Durante aquel tiempo usó también el pseudónimo «Jarilla».

De su colaboración en Marca, MGS redacta en el posterior libro a Manolete cómo vivió la muerte del popular torero:

Con unas cosas y otras, yo me acosté preocupado por la cornada, pero optimista respecto a sus resultados futuros. ¡Y a la mañana siguiente, a primera hora, me despertó mi mujer!

¿No sabes...? A Manolete le ha matado un toro. - ¿Cómo lo sabes?

-Porque lo acaba de decir la radio.

Me tiré de la cama. Ya estaba llamando al piso el chófer de la dirección del periódico, que venía mero que publicamos al día siguiente y que ha constituido uno de los mayores éxitos de Marca. Días después, salí con dirección a Córdoba, para documentarme sobre el terreno acerca de la viday de los comienzos del gran torero fallecido [...]. Por eso nos trasladamos nosotros a Córdoba, en busca 
todo lo concerniente al vivir del diestro fallecido. (1947, sin paginar).

Según sus propias palabras:

El último año que yo hice crítica de toros en Madrid fue en 1947. Ese año mató un toro al «Monstruo», en Linares, y yo vine a Mexico a editar un libro y ya bre de 1969).

Sus años en Madrid y en España llegaron a su fin a finales de los años cuarenta, cuando decide dejar horizonte en México, donde la afición taurina le permitió seguir desarrollando su labor como cronista. Primero emigró él, y años después le acompañaron su mujer y sus cinco hijos.

A pesar de la distancia, con un océano de por medio, en las líneas que MGS no dejó de escribir hasta el final de sus días, siempre encontró la oportunidad para rememorar capítulos de su vida pasada en España, desde su niñez a su etapa en Málaga y en Madrid.

Un ejemplo de su amor por el periodismo lo recuerda en las páginas de su libro sobre Manolete (1947):

Esto era el día de El Imparcial, un periódico cuyo tamano me producia pavor. Pero no me hacia leer [su abuelo] el periódico entero. Su interés se limitaba a dos temas que a mi me resultaban abstrusos e ininy las corridas de toros [ ] Eran los tiempos de guerra de Africa [..]. Mi abuelo me señalaba la el dedo dónde debía yo comenzar la lectura. Yo oía desde el cuarto los juegos de mis amigos en la calle y procuraba leer deprisa para verme libre de aquel suplicio.

Manuel García Santos pasó a la República Mexicana en diciembre de 1947 con la idea muy clara de poner en marcha varios proyectos personales y profesionales.

Fue un español más que arribó a México en momentos complicados, pero hizo suyo este país y en él realizó diversas actividades, involucrándose particu-

larmente en el medio taurino.

Lo primero era buscar refugio y un nuevo espacio para él y su familia, como consecuencia de los duros efectos que la posguerra española seguia produciendo. Este imperativo vital tuvo para él y los suyos afortunada consecuencia.

Por otro lado, sus proyectos como escritor estuvieron, en principio, marcados por la reciente muerte de Manuel Rodríguez, «Manolete» (28 de agosto de 1947), a quien, de forma muy expedita, dedicó un libro que vio la luz en el Madrid de 1947 bajo el título Manolete, el dolor de su vida y la tragedia de su muerte). Su propósito fue alentado, como veremos más adelante, por el entonces banderillero Joaquín Manzanares Antón, que le recomendó viajar a México con objeto de reeditar esa obra, algo que ya no ocurrió

Otro gran anhelo que no llegó a consolidar en su patria, aunque dejó hecha buena parte, era la creación de una revista, de la que practicamente ten acuñados nombre y apellido: El Ruedo de España. Al no consumarlo, como era su deseo, lo puso en práctica en México y la llamó El Ruedo de México loctubre de 1948, con presentaciones intermitentes hasta que tuvo continuidad desde noviembre de 1951 hasta marzo de 1954), publicación emblemática cuya altura reflejó calidad cuantitativa y cualitativa; ambas indudables.

En aquella férrea disciplina que se impuso, escribiendo casi a diario, continuó sus quehaceres en Jueves de Excélsior desde el mismo 1954 hasta quizá 1966, cuando le invitaron a colaborar en El So de México, publicación en la que permaneció hasta 1980.

Vio publicado su libro Juan Belmonte. Una vida dramática (1962) al poco tiempo del suicidio de este en Villa Cerdeña. En El Sol de México, cuyo director fue un militar, José García Valseca, además de sus colaboraciones hebdomadarias en lo taurino -crónica o columna de opinión que llevaba el nombre "Desde mi barrera»-, aparecieron también en form permanente buen número de evocaciones denominadas «iAquel Madrid!», anecdotario inserto en mismísima sección editorial. Se puede a reciar aqui la confianza que el señor García Valseca tuvo en este colaborador profesional, donde seguramente privó afortunada e incondicional amistad.

No conforme, MGS seguía escribiendo en otras No conforme, MGS seguía escribiendo en otras publicaciones, como la revista Toro y El Ruedo en tográfico hoy dí inédito-, dedicado a uno de sus tográfico - hoy día inedito-, dedicado a uno de sus La muere de Manuel Rodriguez er

Lánué de moción más en la posguerra. Esta causante fue un factor que afectó las fibras sensibles de muchos españoles que tuvieron en el diestro cordobes un icono, ese asidero al que acogerse para dar a su toreo y su expresión los tintes de tragedia; también gloria se alejaba de aquel tremendo escenario.
Como confiesa el propio MGS, logra publicar lo que él llamó «un folleto» que reunía las primeras impresiones sobre la vida y muerte de Manolete. Esto se desarrolló en los últimos meses de 1947. Para ello, MGS tuvo en Madrid un casual encuentro con e banderillero Joaquín Manzanares Antón, «Mella», del que nuestro autor da cuenta:

En la puerta de La Tropical me encontré con el banderillero Mella, el que estaba conmigo la noche en meras necibieron en la redacción de $M$ a

- YYa volvió usted de Córdoba?

- Ayer llegué, Mella.

¿Cuabdo publica usted su libro?

¿Por qué?

-Porque se ha escrito tanto en estos días en que he faltado de Madrid y se han cometido tantas in-

discreciones.

$$
\text { - Yo que usted haría una cosa. }
$$

¿Cuál, Mella?

- Tiraría un folleto periodístico, un reportaje, de ese viaje que ha hecho a Córdoba y después me

- ¡A México...! vido Manuel una parte muy interesante de su vida. Manolete en México, y lo escribe allí. ¿Qué le parece...?

No le contesté a Mella. Me fui a la Delegación Nacional de Prensa para que me dieran el papel nediendo una licencia de tres meses en el periódico. Preparé en tres noches el original de mi reportaje. Lo publiqué. Se agotó en veinticuatro horas. Y, diez días después, estaba yo en Cádiz embarcando en el vapor Magallanes rumbo a las tierras calientes y apasionadas de México... (El Ruedo de México, 27
de diciembre de 1951, p. 4).

Y en efecto, por diez pesetas se podía conseguir ¡Manolete! El dolor de su vida y la tragedia de su muerte, folleto que además incluyó un prólogo de Álvaro Domecq y fue enriquecido con dibujos e historietas de Andrés Martinez de Leôn.

Tal impreso nos deja ver que fue hechura fiel de lo que para entonces estaba presentando El Ruedo de España, aunque, por la celeridad con que se elaboró, deja notar algunos descuidos, como la falta de paginación y también la falta del pie de imprenta. Si bien la propuesta que sugirió Mella a MGS sobre publicarlo en México no se concreto, es en México mismo donde finalmente si verá la luz gracias a la publicación por entregas que hizo MGS en E 17 de julio de 1952. Por tanto, la publicación de 63 capítulos se convirtió en el complemento perfecto para tener entre ambos ejercicios el libro que MGS publicó precipitadamente en España antes de su salida a México.

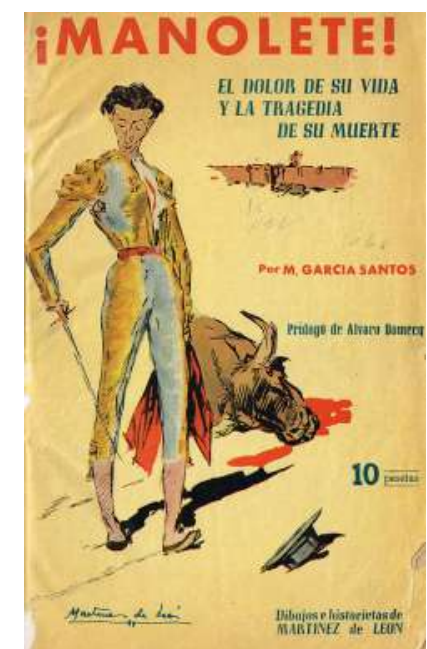

Portada del folleto publicado por Manuel García Santos en 1947.

El Magallanes, que ya había pasado por Nueva York, tuvo que hacer una escala obligada en Cuba y esto a resultas de que, para algunos de sus ocupantes, aún no llegaban los visados para entrar a México. Por eso fue necesario que pasara varios días hospedado en el hotel Saratoga, que estaba enfrente del edificio del Capitolio de La Habana, «que me aprendí de memoria... pues mis paseos eran siempre por aquellos sus jardines». Y en aquella espera, relata MGS:

Una revista de La Habana, Bohemia, al enterarse por el Diario de la Marina de que había llegado yo, te a ción é́ xares cada uno Los escribí Se Manoleren con gran éxito. El Diaro dos enablicacomprar los derechos de mi libro para publicarlo ellos y regalarlo a sus suscriptores. Yo estaba desorientado acerca del valor de la moneda y me pareció poco dinero los tres mil dólares que me daban por aquellos derechos. Y no accedí. (El Ruedo de México, 3 de enero de 1952, p. 4).

Ya con el visado, tomó un avión que más tarde aterrizo en Mérid después, arribar a la ciudad de Mexico. Se hospedó en el hotel Mancera, en la calle de Venustiano Carranza. Sus propias palabras recogen el momento de la llegada: «iHabia llegado al final de mi etapa, y al comienzo de mi aventura en America.....

MGS llegó a la ciudad entre el 15 y el 17 de diciembre de 1947, según se deduce por lo leído en el capitulo XVII de su "iManolete...? El dolor de su vida y la tragedia de su muerte», versión que se 
publicó en El Ruedo de México el 10 de enero de 1952. Conviene aclarar, como dato anecdótico, que su arribo sucedió pocos días después de la seria cornada que recibió Manolo dos Santos en el ruedo de la plaza de toros El Toreo (estado de México) la tarde del 14 de diciembre. Se desarrollaba la tercera corrida de aquella temporada y el portugués recibía la alternativa de manos de Fermín Espinosa, "Armillita», y como testigo Carlos Arruza, con toros de Pastejé. Fue Vanidoso el que a los pocos minutos de la ceremonia le prendió por el muslo derecho, atravesándole la femoral, por lo que aquellos momentos se cubrieron de profunda intensidad.

Desde aquella segunda quincena del año 1948 hasta el 5 de abril de 1980, en que muere, el quehacer de MGS fue muestra de una intensa capacidad de disciplina, conocimiento, el de un convencido de que el periodismo tenía, en tanto forma de difundirlo, que llegar hasta el común de un sector de aficionados que conocieran no solo la parte emotiva, sino también la técnica, en la que puso marcado énfasis, sin soslayar el efecto estético en que podrían maticonvirtió en su principal arma de difusión.

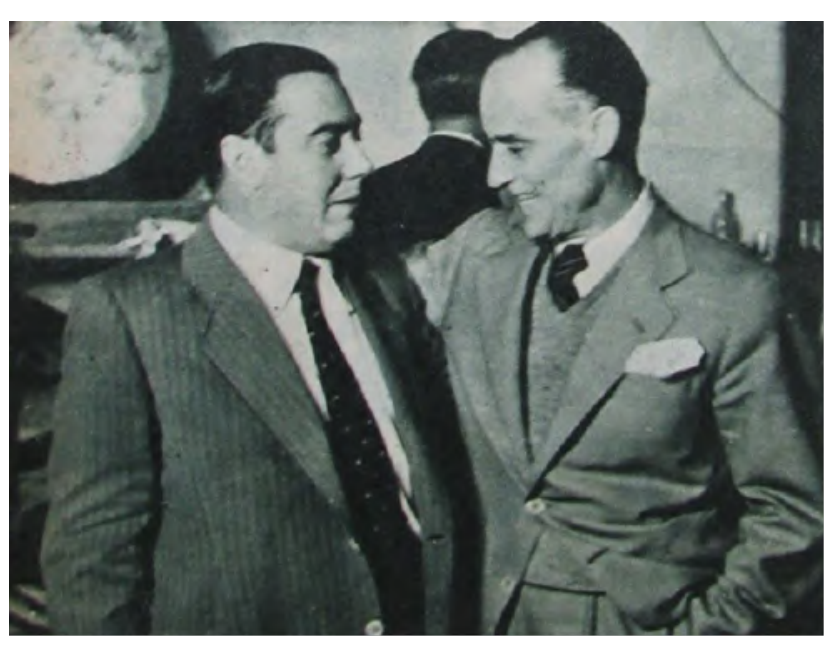

En la imagen, Miguel Atienza -picador de toros-y Manuel García 31 de enero de 1952, p. 20).

A cuarenta años de su desaparición, es de gran estima ponerlo en valor con toda la carga delimpresionante legado que dejo en publicaciones como El Redondel o Jueves de Excélsior. Sin embargo, lo que quedó impreso en El Ruedo de México representa la suma de toda una experiencia acumulada de sus primeros cincuenta años. La impronta de MGS en dicha publicación -que va de 1948 hasta 1954- representa la materialización de un proyecto largamente acariciado, donde logra, además, reunir a un conjunto muy valioso de colaboradores, el que, si bien no era muy amplio, sí determina hacia dónde quería conducir tal empresa. Entre ese grupo selecto, se encontraban el doctor tín González, «Escopeta», el joven Manuel Mejido y ambién los hermanos Mayo, fotógrafos connotados de origen gallego -Paco, Cándido, Faustino, Julio y Pablo-, teniendo a su lado al no menos importante Julio Souza Fernández. Se incorporaron como ilusradores Andrés Martínez de León y Benito Vázquez. Tres de los cinco hijos de MGS, Pedro, Antonio y Manuel García Suárez, se incorporaron al quehacer periodístico, gestando un conjunto de actividades que dejan ver el hecho de que aquello se convirtio en un compromiso familiar que realizaron a cabalidad.

Su hijo Antonio decidió la aventura de hacerse novillero y recibió el apoyo de su padre, que contribuyó a través de las páginas informativas a la cobertura de sus actuaciones. Se retiraría finalmente en un festejo donde actuaba la rejoneadora de moda Juanita Aparicio, en la plaza México, un 25 de septiembre de 1955

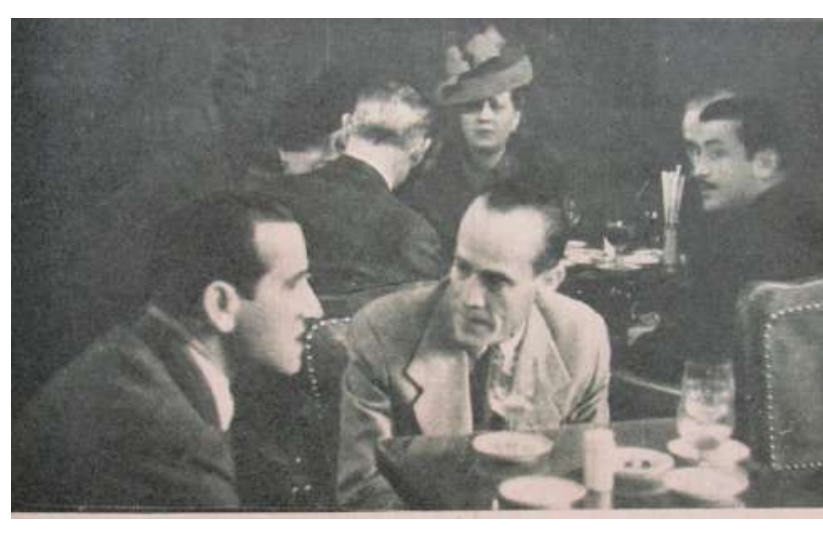
«De todas estas cosas hablábamos Belmonte y yo en Gayango, en
aquella Feria de Sevilla que fue memorable por tantas cosas, y la
principal de todas ellas, porque allíse consagró Manolete como principal de todas ellas, porque allíse consagró Manolete como de 1952, p. 3).

Anterior a él, ya estaban asentados en nuestro da»- o Enrique Bohórquez y Bohórquez como los spaños más connotados que realizaban su labor fundamentalmente en el medio taurino. José Alameda había llegado a México el 1 de marzo de 1940 y muy pronto comenzo a buscar las formas los medios para establecerse, lo que hizo de manera definitiva y afortunada. Sus primeros pasos fueron apoyando al antropólogo Jacques Soustelle luego tuvo oportunidad de participar en intervenciones radiofónicas, primero en la XEBZ. Tal fue su manera de desplegar sus conocimientos y su bie ron a personajes como Emilio Azcárraga Vidaurreta, propietario de la radiodifusora más célebre en aquel entonces, la XEW, integrándolo en el reparto de las celebridades. También pudo formar parte de la exitosa Radio Mil.

Con dieciocho años de diferencia entre la llegada de José Alameda y García Santos, este factor pudo influir en la aventajada presencia del madrileño sobre el MGS. Al desarrollar cada quien su ejercicio, no tuvieron, como puede entenderse, ningún conflicto; es más, hubo respeto mutuo. Fue el propio José Alameda, dos días después de que MGS dejara de existir, quien publicó en su conocida columna «Signos y contrastes» una apreciación que co uno con

Signos y Contrastes

Se ha ido un

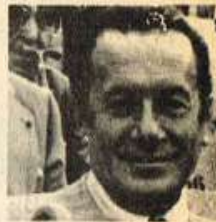

Taurino Auténtico

Por José Alameda

En tierra mexicana, donde transcurrib la lútima etapa de su existen-
cia, descansa ya para siempre nuestro colega y ymigo Manuel Gercia San.

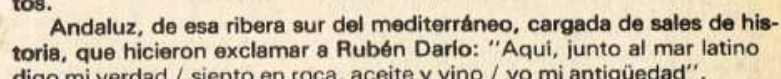

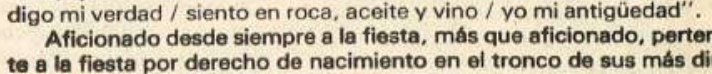
to a la fiesta por derecho de nacimiento en el tronco de sus más directas
tradicioneses.

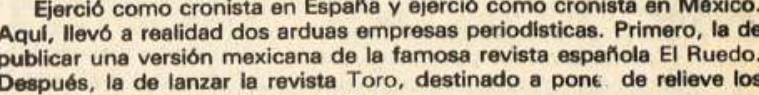

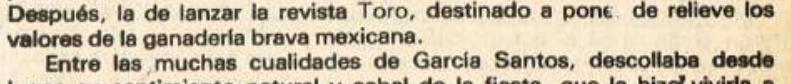

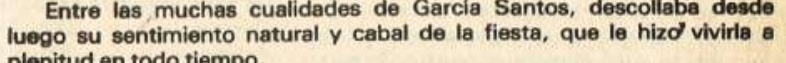

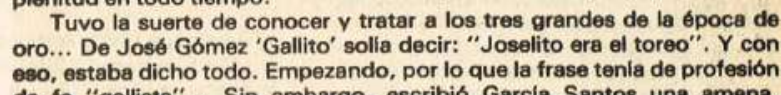

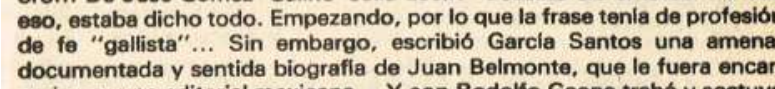

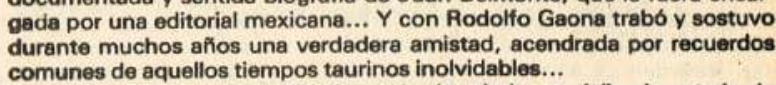

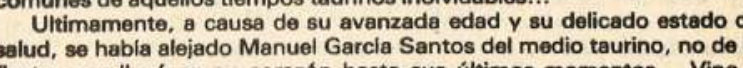

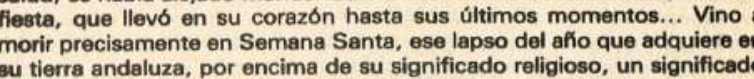

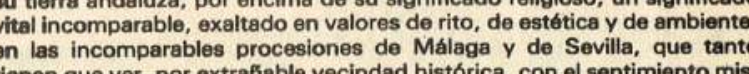
cienen que ver, por extrafiab
mo ode la fiesta de los toros. con tanta frecuencia. Pero la separación material no me mizo olvidar

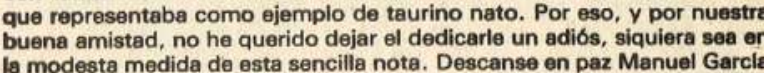

Atículo publicado por el periodista José Alameda tras la muerte de Manuel García Santos. (Fuente: El Heraldo de México, 7 de abril de 1980, p. 8B).
Concluida la aventura de El Ruedo de México, pronto encontró espacio en Lunes de Excélsior donde siguió publicando crónicas y columnas hasta que el 10 de marzo de 1966, hasta poco antes de su muerte, ya en abril de 1980, fue acogido por el militar revolucionario, dueño de una importante fortuna y también periodista José García Valseca en la nueva edición de su corporativo, conocida como $E$ Sol de México. Allí, casi a diario, no dejó de colaboque se enriqueció columna «Desde mi barrera», la (cuya primera entrega sucede el 25 de abril de 1967) y posteriormente «Este México» (que apareció en agosto de 1968). Evidentemente, no puede ignorarse todo un conjunto de crónicas tanto para novilladas como corridas de toros.

En el curso de 1962, nuestro autor tiene la fortuna de publicar el libro Juan Belmonte. Una vida dramática, cuya edición alcanzó un elevado y exitoso tiraje de 40.000 ejemplares. Solo se tiene referencia de otro con tamaña difusión. Me refiero a Mis veinte años de torero. El libro íntimo de Rodolfo Gaona, en el que dos ediciones de 1924 y una más de 1925 sumaron 33.000 ejemplares. Sobre una cuarta reedición, la de 1964, se desconoce por ahora lo que salió de imprenta, aunque debió ser, por la sola referencia del Indio Grande -uno más de esos sobrenombres con que se conoció al célebre torero Gaona-, motivo para una edición importante.

En 1965, se publicó un conjunto de varios números de una revista que se titulaba Toro. En esa efímera aventura, MGS jugo el papel de director literario. En dicha edición, quedó la insinuación de otro libro de su autoria que anunciaban como Tres epocas del toreo... Belmonte, Manolete, el Cordobés. Queda, ante esto, confirmar si existe o no el manuscrito mecanuscrito, en propiedad de su hijo Manuel.

Conviene apuntar que, siendo la radio un medio de comunicación que entonces gozaba de buena cobertura, permitio que MGS participara en diversos programas en la XERH, con una frecuencia de $1500 \mathrm{KHz}$, radiodifusora concesionada a Arsenio Tuero, hermano del celebre "baritono de Argel», Emilio Tuero, que causó furor por su entonada voz, así como por sus dotes de actor en célebres cintas durante

conforme con las actividades que realizaba cotidianamente, puso en marcha otro proyecto que correspondió a la elaboración de un guion cinematográfico dedicado a Rodollo Gaona. La amistad que Garcia Santos mantuvo con el Indio Grande fue entranable, de ahi que el tambien conocido como Califa de León escribiera sentidas palabras en el prólogo del libro dedicado a Belmonte.

El estilo de MGS es sencilo, sin complicaciones, y nutre de datos, recuerdos, anécdotas y otras tan- 
tas vivencias. Matizaba cada colaboración con toques inigualables. Y aquí un ejemplo. Justo en su primera columna «iAquel Madrid!», recordaba bajo rez de Ayal Gómez de la Serna y Menéndez Pidal al abordar el suicidio de Juan Belmonte.

[...] Un periodista se comunicó por teléfono con la casa de Perez de Ayala, se puso al aparato la esposa del escritor:

-Señora: Quisiera unas palabras de don Ramón acerca de la desgracia que ha ocurrido en Sevilla.. - Mire: Mi esposo está tan afectado que no pue de ponerse al teléfono. Él quería mucho a Juan y algunos días, a ver si está en condición de contestarle.

Pérez de Ayala no se repuso nunca de la impresión sufrida. El dolor por la muerte de Juan le aceleró el viaje sin retorno. Y unos días antes de mori cuando lo interrogaba un reportero acerca de did humana de Belmonte, le contestó:

- Extraordinaria...! iComo no he visto otra...! Y un gran amigo para los trances dolorosos... A mí, $c 0$, Juan me ha sacado de él.. YY han sido tantas co, Juan
veces!...

Con su obra tan extensa como valiosa, Pérez de Ayala sufrió penurias. Se habían ido ya las épocas de «el índice». Pero Ramón no gozó nunca bienestar material ni obtuvo grandes liquidaciones de los editores. Parecia como si aquel su error primero del A. M. D. G. lo hubiera perseguido hasta la muerte... (EI Sol de México, 25 de abril de 1967).

Entre los periodistas mexicanos con quienes alternó por aquel entonces, estaba un selecto grupo en el que se encontraban Roque Armando Sosa Ferreyro, Manuel Horta, Armando de María y Campos, Carlos Septién García, Rafael Solana -padre e hijo-, Abraham Bitar y Alfonso de Icaza, que eran, entre otros, los más representativos.

Hoy día es difícil que los viejos aficionados recuerden la labor de tan notable personaje, así como el empeño de sus propósitos basados en una profunda explicación y justificación técnica de la tauromaquia. Si el sintoma se percibe en esa forma, las nuevas generaciones no tienen simple y sencilla-

${ }^{4}$ MGS se refiere a la primera obra escrita por Ramón Pérez de Ayala, la cual fue prohibida de inmediato por los jesuitas, pues ros y aquel estilo personalísimo que tuvo. En ella quedaron sus recuerdos, precisamente los del colegio de jesuitas de Gijón, donde cursó sus primeros estudios. En tal obra destacan la disci-
plina estricta y los procedimientos restrictivos de la personalidad que empleaba el profesorado. Para un niño, aquel régimen de estudios, de recreos, de horarios inflexibles resultaba tiránico. Los jesuitas no quisieron o no pudieron ver esa circunstancia y
A. M. D. G. se proscribió. mente idea de todo aquel buen hacer, de la crónica ejemplar, del análisis a fondo que iba de valorar a toro, las fenas y demás circunstancias, matizando eroscrito con sabrosasy circunstancias, valizando daban por resultado la crónica impecable.

Como todo conflicto bélico, la guerra civil española causó entre quienes la vivieron y la padecieron un trauma grabado a fuego, cuyo tatuaje, imborrable, aún pesa. El amargo episodio del encarcelamiento de MGS, uno más de los que lo padecieron, le im pidió irse a México, elección que mostraba su impecial inclinación por un país que comenzaba a dar señales de solidaridad humanitaria.

Tras aquel episodio (López Romero, 2020), se permite observar que entre marzo de 1937 y diciembre de 1947 transcurrieron diez años difíciles, complicados para quien -como muchos- tuvo que asumir incluso las secuelas de la posguerra. Y en ese diciembre del año 1947 se cumplió el anhelo. Desde luego que Manuel tendría muy armado el bagaje taurino de «Este México» -si nos atenemos al título de otra de sus columnas-, por lo que, al establecerse desde aquel 15 o 17 de diciembre de 1947 llegaba a un territorio conocido. Esto debió serle de mucha utilidad para concretar diversas aspiraciones profesionales y también familiares.

Sin dejar pasar mucho tiempo, para octubre de 1948 ya estaba circulando la célebre revista El Ruedo de México, la cual tuvo una aparición intermitente que se estabilizó a partir del número 30 , el que ya estaba en los puestos del periódico desde junio de 1951, alcanzando su última edición, la del 15 de marzo de 1954, el número 141

De lo anterior deben mencionarse incontables muestras en ese conjunto de publicaciones que fueron, y aún son, fuente de información invaluable que apuntaron a diversos puntos que implicaban dejar un aprendizaje claro sobre la tauromaquia. Para ello, fueron necesarios el despliegue del conocimiento personal de su director y la posibilidad de diseminarlo en diversas colaboraciones, como es el caso, por ejemplo, de que los propios jueces de plaza contaran con un espacio para el desahogo de lguna duda como resultado de su participacion. Si en España los referentes noticiosos como Soly Sombra, La Fiesta Nacional, El Ruedo fueron guía de información y conocimiento, en México debe recordarse, entre otros, El Arte de la Lidia (desde 1884 luego en forma intermitente hasta 1901), La Muleta (1887-1889), El Toreo Ilustrado (1895-1899) y ya en el siglo XX Ratas y Mamarrachos (1901-1911), Mexico Taurino (1904-1908), El Universal Taurino, Toros y Deportes y El Taurino (1921-1929), El Eco Taurino
(1925-1939), La Lidia (1942-1945, 1945-1951), hasta llegar al Ruedo de México, sin que esto ignore otro conjunto muy valioso del que se valieron y hoy nos valemos para el mismo propósito de formación e información.

No cabe duda de que, sin exaltación alguna, lo hecho por Manuel García Santos fue, a lo largo de treinta y tres años, lo que todo periodista honesto debe hacer cuando dispone de un medio para difundir sus ideas. Y en eso cumplió a cabalidad.

En palabras de su hijo Antonio García Suarez, residente en la ciudad de México, García Santos fue un romántico, un bohemio, nunca le interesó el dinero. Le gustaba mucho Chávez Nogales. Siempre fue un taurino ciento por ciento 5 .

\section{Fuentes ybibliografía}

Alameda, J., "Carlos Fernández y López-Valdemoro» (1953): El toreo, arte católico (con un apéndice sobre a la muerte, prólogo la poesia taurina) y Disposición cepresidente del Casino Español y presidente de su Comisión de Acción Cultural). México: Publicaciones del Casino Español de México.

(1980): «Se ha ido un taurino auténtico», en Heraldo de México, 7 de abril.

Cortés Salido, J. (1952): Memorias, casi de memoria. Málaga: Dardo.

El Ruedo de México, 29 de noviembre de 1951 García Galindo, J. (1995): Prensa y sociedad en Málaga.

Entrevista a Antonio Garcia Suarre,
tos. México, 31 de marzo de 2017 .
(1999): La prensa malagueña 1900-1931. Málaga: Ayuntamiento de Málaga.

García Galindo, J. A.; Lopez Romero, l.; y Novas Martín, G. (2016): «La represion de periodistas durante la guerra civil española: Los casos de Eduardo León y Serralvo y de Rosendo Corripio Márquez (1936-1937)», en AlLópez, J. V. (eds.): Perfiles de periodistas contemporá neos, pp. 159-172. Madrid: Fragua. García Santos, M. (1947): ¡Manolete! El dolor de su vida y la trag
edición)

(1962): Juan Belmonte. Una vida dramática. México: Populibros La Prensa.

-(1964): Lunes de Excélsior, 10 de agosto.

López Romero, I. (2020): 27 de septiembre. lagueña conservadora al inicio de la guerra civil: el declive de la Unión Mercantily, en Communication \& Society, 33 (2), pp. 91-104.

Morales Muñoz, M. (2008): «Entre el cielo y la tierra: la represión franquista en Málaga», en Baetica: Estudios de Arte, Geografía e Historia, 30, pp. 431-445.

rozo Fernández, M. C. (2001): La depuración del magisterio nacional en la ciudad de Málaga. Málaga: Diputación Provincial de Malaga.

gado militar número 15. Caja 637. Archivo Juzgado Togado Militar de Málaga.

Ramón Carrión, J.L. (2010): «La revista El Ruedo, treinta tres años de información taurina en España (19441977)», en Revista de la SEECI, 21, marzo, año XI, pp. 94-121.

Vázquez, A. (2011): La mirada de Málaga: Historia y vida de 20 familias malagueñas. Málaga: Ediciones del Ge

\section{Fuentes personales}

Sarcia Santos. México D. F., 31 de marzo de 2017. 